\title{
Correspondence
}

The Editor,

fournal of Glaciology

SIR,

\section{Imaging of uncoated snow crystals using a low-vacuum scanning electron microscope}

Imaging and characterization of snow aggregates using a scanning electron microscope (SEM) has routinely employed coating the specimens with aluminum (Wolff and Reid, 1994), gold (Ghermandi and others, 1999), gold and palladium, or platinum (Wergin and others, 1995, 1996a, b). Certainly the procedure has merits, but, as will become apparent below, coating the snow crystals is not always necessary. In support of our claim we present the SEM images in Figure 1. These images are part of a much larger collection and were obtained without the prior application of a conductive coating.

The imaging procedure involved a JEOL JSM-5310LV low-vacuum SEM equipped with a custom-made cold stage cooled by nitrogen gas flowing through a liquid nitrogencooled coil. The energy of the electron beam was $10 \mathrm{KeV}$. A $2.5 \mathrm{~cm}$ diameter brass disk with a slightly elevated rim was mounted on the cold stage and cooled down to $-170 \pm 5^{\circ} \mathrm{C}$. The disk was then removed and placed in an insulated container, which in turn was placed in a small cooler where all its surfaces were covered with cold packs. The specimens consisted of fresh snow collected during or shortly after snowfalls from the immediate vicinity of the laboratory in Hanover, New Hampshire (February-March 2002). The temperature of the air on the ground at the time the snow was collected was $-4^{\circ}$ and $-1^{\circ} \mathrm{C}$, respectively. Using a pair of tongs, the cold brass disk was inserted slightly below the surface of the snow cover and then lifted. The snow sample was then placed in the insulated container and was immediately transported to the room hosting the SEM. The brass disk containing the snow was rapidly remounted on the cold stage, and the SEM chamber promptly evacuated. An image was acquired within approximately $3 \mathrm{~min}$ after the snow sample was introduced into the SEM chamber. With few exceptions, only one image was acquired per snow load. The process was repeated several times, each time with freshly collected snow.

In order to allow for an objective comparison, the features presented in Figure 1 were selected to match some of the types of crystal aggregates and individual snow crystals imaged by Wergin and others $(1995,1996 \mathrm{a}, \mathrm{b})$. These types included individual or assemblies of flat hexagonal plates (Fig. la and b), collections of short prismatic ice crystals held together by a matrix (Fig. lc and d), sinuous metamorphosed dendritic forms exhibiting bonding or sintering with the adjacent crys- tals (Fig. le) and asymmetric crystals (Fig. lf). The comparative analysis of the images revealed that in the context of the procedure described above, the absence of a metallic coating, at least for the categories represented in Figure 1, did not result in a reduction of the level of detail compared to similar observations on coated snow crystals. The technique presented in this work has the advantages of being simple and inexpensive in the context of providing a reasonable level of detail comparable in some cases to coated crystals. Moreover, the technique employed here allows for the use of energydispersive spectroscopy (EDS), as well as for real-time observations of a variety of sublimation-induced morphological changes in the snow aggregates. Figure lc and d show collections of prismatic crystals being slowly exposed as the matrix in which they are embedded (possibly a frozen water droplet (Wergin and others, 1995)) sublimates away. The images, especially the one in Figure ld, clearly demonstrate that the prismatic crystalline structures (replicating to some extent the symmetry of $I_{h}$ ice lattice), due to a much lower surface energy, sublimate at a significantly lower rate compared to the surrounding matrix.

Finally, the image in Figure if shows what appears to be a dendritic structure. Note the low-angle sub-grain troughs.

Thayer School of Engineering,

DANIEL ILIESGU

Dartmouth College, IAN BAKER

Hanover, New Hampshire 03755-8000,

U.S.A.

E-mail:daniel.iliescu@dartmouth.edu

\section{August 2002}

\section{REFERENGES}

Ghermandi, G., P. Laj, M. Capotosto, R. Cecchi and C. Riontino. 1999. Elemental and mineral characterization of coastal Antarctic aerosols in snow using PIXE and SEM-EDAX. Nucl. Instrum. Methods Phys. Res., Ser. B, 150, 392-397.

Wergin, W. P., A. Rango and E. F. Erbe. 1995. Observations of snow crystals using low-temperature scanning electron microscopy. Scanning, 17 (1), 41-49.

Wergin, W. P., A. Rango and E. F. Erbe. 1996a. The structure and metamorphism of snow crystals as revealed by low temperature scanning electron microscopy. Proc. East. Snow Conf., 53rd Annual Meeting, 1-3 May 1996, Williamsburg, Virginia, 195-204.

Wergin, W. P., A. Rango, E. F. Erbe and C. A. Murphy. 1996b. Low temperature SEM of precipitated and metamorphosed snow crystals collected and transported from remote sites. F. Microsc. Soc. Am., 2(3), 99-112.

Wolff, E.W. and A. P. Reid. 1994. Capture and scanning electron microscopy of individual snow crystals. F. Glaciol., 40(134), 195-197. 

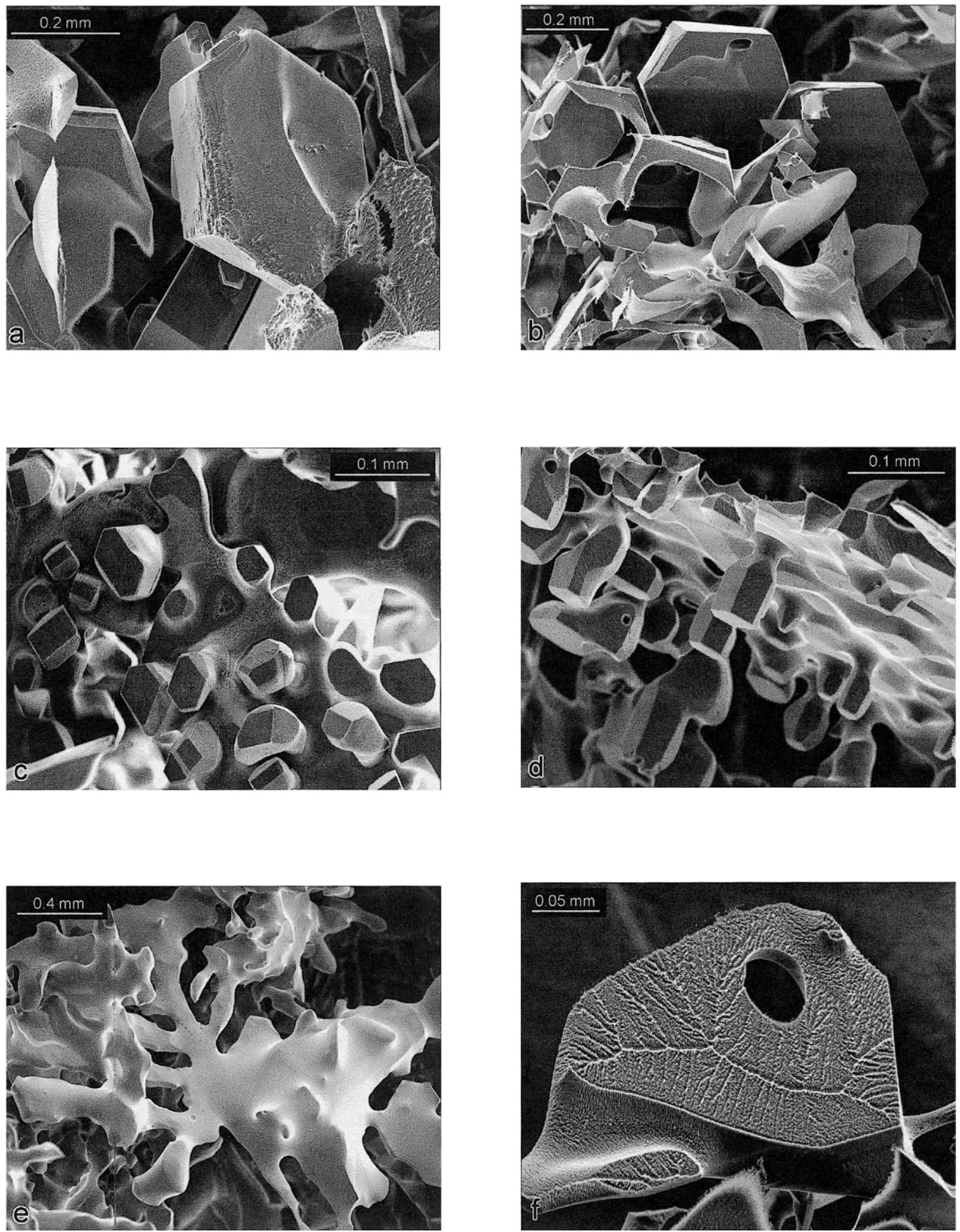

Fig. 1. SEM images of four types of crystal aggregates and individual snow crystals obtained without a conductive coating. The thin vertical lines visible mostly on the right side of the images are artifacts caused by a malfunction of the image acquisition software. $(a, b)$ Flat hexagonal plate-crystals; $(c, d)$ prismatic crystals embedded in a matrix; $(e)$ rounded metamorphosed dendritic forms; $(f)$ possible asymmetric dendritic features. 